\title{
Scholarly Views on Theory: Its Nature, Practical Application, and Relation to World View in Business Research
}

\author{
Jason Earl Thomas ${ }^{1,2}$ \\ ${ }^{1}$ School of Business and Communications, Concordia University Texas, USA \\ ${ }^{2}$ Colangelo College of Business, Grand Canyon University, USA \\ Correspondence: Jason E. Thomas, Schoole of Communication, Concorida University Texas, Austin, USA. Tel: \\ 1-512-655-3038. E-mail: jason.thomas@concordia.edu
}

Received: July 6, 2017

doi:10.5539/ijbm.v12n9p231
Accepted: August 8, 2017

Online Published: August 20, 2017

\begin{abstract}
Understanding theory, its practical application, and how to select a theoretical framework for research studies is often a challenging problem for new graduate and doctoral business students. As these students explore theory use in various fields and the general academic body of knowledge, this task can become even more daunting and confusing. There does not appear to be a common definition of theory across or within different disciplines. Further, scholars disagree on the value of theory and its practical application. This paper explores the scholarly nature of theory, its application, and its relationship to world view. Examples and a discussion are provided to better help students absorb this important yet ambiguous topic.
\end{abstract}

Keywords: theory, practical application, world view, theoretical framework

\section{Introduction}

Doctoral and graduate students are often introduced to theory and research at the beginning of their programs. For novice researchers, exploring theoretical concepts and identifying a theoretical framework can be challenging, if not confusing. Thesis students often struggle to define their problem statement, purpose of the study, significance of the study, and study methodology. Once students move on to aligning these critical beginning sections of the study document, they begin to explore identifying the theoretical framework for the study. It's at this stage that the stereotypical "analysis paralysis" and panic set in.

This paper examines the role of theory in research by identifying and exploring world views on theory, discussing how research contributes to theory, and providing a tangible example of theoretical contributions to the field of business. Theory is an integral part of scholarly research, providing both guidance and exploration of the relationships among phenomena. Despite the recognized importance of theory in research, universal agreement does not exist among scholars about what constitutes a theory (Harlow, 2009; Sutton \& Staw, 1995).

\section{Methodology of Literature Review}

This literature review was conducted in accordance with the recommended principles of a systematic literature review (Jesson, Matheson, \& Lacey, 2011):

1. Field mapping by means of scoping review

2. Searching comprehensively

3. Extraction of data

4. Synthesis of data

5. Writing up findings and discussion.

A research plan was developed utilizing research questions, keywords, and sets of inclusion and exclusion criteria. The goal of the project was to examine how theory is defined, used, and created in scholarly literature. The research questions included the following:

1. What is the definition of theory?

2. How do scholars use theory? 
3. How does theory contribute to practice?

4. How are theories created?

5. How does world view contribute to theory?

Keywords were used to conduct searches for relevant peer-reviewed literature and other academic sources. Sources for research included online libraries and databases such as Proquest and GoogleScholar, as well as general Internet searches. After all relevant data were gathered and analyzed, findings were summarized.

\section{Presentation of Findings-Literature Review}

\subsection{What Constitutes Theory}

The word "theory" comes from a Greek verb meaning "contemplate." Though scholars disagree on the finer points of theory, all seem to agree on a basic definition: theory is a description of a phenomenon and the interactions of its variables that are used to attempt to explain or predict. However, in attempts to clarify the definition, scholars' views vary on what constitutes a theory and its purpose, as well as what makes a good theory (Gelso, 2006; Harlow, 2009; Stam, 2007, 2010; Sutton \& Straw, 1995; Wacker 1999; Weick, 1989, 1995).

Parsons (1964) states theory as "a system of laws “(p. 485). For Galtung (1985), "a theory is a set of assumptions structured by a relation of implication or inference" (p. 451). Kaplan (1964) defined theory as a group of related generalizations that indicate new observations, which can be empirically tested for the purpose of explaining or predicting. According to Littlejohn (1989), any attempt to explain or create a representation of an aspect of reality is a theory. Stam (2007) defined a theory as the systematic organization of knowledge, which can be applied for the purpose of problem solving. Malmi and Granlund (2009) offered another definition: "By theory we mean a general statement subsuming a series of phenomena" (p. 623). Grounded theory provides a qualitative method for developing theory in management (Fendt \& Sachs, 2008; Ng \& Hase, 2008). Because theory is a complex subject, some may confuse theory with its components or the process of theorizing (Weick, 1995); consequently, it is important to distinguish theory from related terms such as hypothesis, model, paradigm, and concept.

A paradigm is a framework of beliefs or world views used to define the values, methods, or boundaries for research (Mink, 1992). Paradigms can define what is important or not important and what is possible or impossible (Ratcliffe, 1983). Paradigms can be compared to overarching philosophies and are a significant view of a theory. Ratcliffe (1983) stated that paradigm, theory, standards, and method are an inextricable mixture.

A hypothesis is an educated guess with predictive value about how something will work using observation or previously held knowledge (Sutton \& Staw, 1995). In contrast, a theory is a strongly substantiated and unified explanation for a set of proven hypotheses (National Academy of Sciences, 1999). Moreover, a hypothesis must be specifically testable, whereas a theory does not. Simply put, a hypothesis is a single component of a theory.

A model is a tool used to facilitate theory construction, typically a written or graphic representation of a theory or one of its components (Shoemaker, Tankard, \& Lasorsa, 2004). A model, however, does not explain things; it merely illustrates or provides a method to explore a theory (Shoemaker et al., 2004). For example, when working on a theory regarding nuclear fusion, one might construct a molecular model. The model would be useful for seeing how the components of atoms might be positioned or interact; however, the model alone would not provide an explanation.

A theoretical concept is a building block on which a theory is constructed (Shoemaker et al., 2004). Concept refers to how data are described or interpreted, literally the items being studied, compared, or related to one another (Shoemaker et al., 2004). For example, education is a concept that describes the sum of a person's learning experience. A concept is not a theory, but a method of description used in theoretical work.

The question of what constitutes a theory is not simple to answer, as different scholars (Gelso, 2006; Harlow, 2009; Henderikus, 2007) have different views about what a theory is, especially in more detailed discussions about what constitutes theory. According to Gelso (2008), theory is a combination of different constructs, such as descriptive ability, explanatory power, heuristic value, testability, integration, parsimony, clarity, comprehensiveness, and delimitation. He believed that theory is actually refined through research and that understanding these constructs enables theory refinement (Gelso, 2008).

Conversely, Harlow (2009) was of the opinion that theory has no distinct or fixed meaning and that the purpose of a theory is to suggest a determining law or set of laws. Wacker (1998) presented a different meaning of theory: "Operationalization of the definition of theory should directly be tied to the necessary components of theory" (p. 363). Harlow provided four constructs of a theory: (a) definitions, (b) a domain of applicability, (c) a set of 
relationships or variables, and (d) specific predictions or factual claims.

Yet again, when discussing how to formulate theory, scholars differ. Gay and Weaver (2011) stated that the researcher and researcher assumptions determine the approach of theory to be applied. On the other hand, according to Lynham (2002), the conceptual development of a theory is an "informed conceptual framework that provides an initial understanding and explanation of the nature and dynamics of the issue, problem, or phenomenon that is the focus of the theory" (p. 231). Similarly, DiMaggio (1995) stated, "There are at least three views of what a theory should be: (a) theory as covering laws, (b) theory as enlightenment, and (c) theory as narrative" (p. 391). Scholars seem divided on whether theory development is a rigid process or needs to be developed according to the work at hand.

According to Stam (2007), three world views of theory that have been influential for many decades are (a) reductionism, (b) instrumentalism, and (c) realism. Reductionism states that a complex system is merely the sum of its parts and that one can learn about the whole by examining the individual pieces (Burgelman, 2011; Link 2000; Stam 2007). Reductionists attempt to make complex items more understandable by studying their individual parts (Link, 2000; Nadler, 2004; Wood \& Caldas, 2001). In breaking down components, reductionists hope to realize a new view of the system base. Nadler (2004) provided four guiding principles for a reductionist approach. First, all things can be separated into their components. Second, any of those components may have substitutes. Third, solutions for partial problems can help solve whole problems. Fourth, the whole entity is nothing more than the sum of its parts (Nadler, 2004).

Instrumentalism states that theories are useful instruments in understanding the world and are best defined as nothing more than mere instruments (Caldwell, 1984). In essence, a theory should be evaluated for its ability to be used to predict or explain a phenomenon rather than its ability to utilize it to depict reality (Davies, 2008). One example of this view is an examination of acupuncture. Some individuals swear by acupuncture's effects, even though they might not believe in the principles expressed by art, such as Ki energy. An instrumentalist would say that it doesn't matter why it works as long as it works.

A third world view offered by Stam (2007) as influential in theory development is realism. Realism states that the world can be described in terms of science - that there is a real view of the world independent of perception (Ramoglu, 2013). Generally, realists assert that one can make reliable predictions about unobservables (Ramoglu, 2013). One example of an application of this view is Copernicus's heliocentric theory that the Earth revolved around the sun, even though there was no way to observe the phenomenon.

\subsection{Relationship between Research and Theory and How Research Contributes to Theory}

The purpose of theory is to predict or explain (Fischer, 2010; Gelso, 2006; Harlow, 2009; Stam, 2007, 2010; Wacker, 1999). Theory is used to conceptualize and explain a set of systematic observations on phenomena and complex behaviors. Research is "the systematic process of collecting and analyzing information (data) in order to increase our understanding of the phenomenon about which we are concerned or interested" (Leedy \& Ormond, 2005, p. 4). According to Ellis and Levy (2008), research is basically the process of collecting and analyzing information to develop knowledge, and "for any endeavor to be considered research, it must clearly present the potential for creating identifiable new knowledge" (p. 23). According to Wacker (1999), the two purposes for research are fact finding and theory development. Simply, theory is the foundation of research, while research helps in refining the theory.

Theory and research have a symbiotic nature tying them together. The development of theory relies on research and, likewise, research relies on theory (Fawcett \& Downs, 1986). According to Harlow (2009), the term "retroduction" was created to describe the interplay between theory and research. Retroduction is the cyclical process whereby a researcher tests theoretical ideas against new data as they emerge and then reframes the ideas if necessary or retests the ideas until the resulting conclusions are viewed as trustworthy (Harlow, 2009).

Gay and Weaver (2011) affirmed Harlow's stance, stating, "Research knowledge tends to contribute to theory more incrementally, building upon, and adding to a lexicon of facts" (p. 29). Problem definition is the connection point between theory and research, and the theory to be tested defines the path and strategy of the research (Harlow, 2009). Here again, scholars are divided. Holten and Lowe (2007) touted the importance of theory over research by stating, "It is deductive theory that has the greatest potential for advancing science because it often proposes new constructs and relationships that spur other researchers to conduct new empirical research to verify the theory" (p. 304). Conversely, whole research methodologies exist for the purpose of theory creation, such as grounded theory. Essentially, theory provides explanations or predictions about the world, and research is used to discover, explore, understand, validate, or refute theory - the two are inarguably linked. 
Two methods for conducting research are quantitative and qualitative. Quantitative research refers to the empirical investigation of phenomena by means of mathematical and statistical techniques (Creswell, 2009). Qualitative research refers to the attempts to understand the deeper meaning around the complexities of human interaction (Creswell, 2009; Ratcliffe, 1983; Thomas, 2017). Both methods are used in research and contribute to the development of theory. These methods can also be combined in a mixed methods study (Creswell, 2009). In a mixed methods study researcher gather information for qualitative methods and input them directly into quantitative research. However, a full discussion of mixed methods research is beyond the scope of this discussion.

According to Aliaga and Gunderson (2000), quantitative research is explaining phenomena by means of the collection of numerical data for the purpose of analysis using mathematical methods. Quantitative methods convert data into a mathematical or measureable form. This creates an opportunity to easily categorize and work with data. The concept is similar to the manner in which computers convert all data to binary constructs. This categorization allows to a researcher to answer specific questions from complex data sets (Aliaga \& Gunderson, 2000). For example, quantitative methods can easily produce a result to answer the question of how many males aged 18 to 35 earn more than $\$ 50,000$ per year. Quantitative research has a strong reputation, even in the social sciences, where early critiques of the lack of a core knowledge base of empirical data created a movement for social science researchers to attempt to demonstrate adherence to hard science methods, like the positivist approach, using more quantitative techniques (Austin, 1978).

Quantitative methods contribute to theory by providing specific and measurable ways to view, access, and analyze data. This measurability adds to theory development because quantitative studies can enable trend spotting. Du and Kamakura (2012) found that a multivariate quantitative approach to trend spotting is a useful method of gathering market intelligence for creating and refining theory. Quantitative models have been a default tool for operation management research for many years (Bertrand \& Fransoo, 2002).

Theories are often developed by making frequent observations over time and are then used to generate a construct that can further explore the phenomenon. Qualitative methods provide the means to measure, document, and analyze these observations (Edmondson \& Mcmanus, 2007). Data from qualitative studies can inspire the creation of new theory and can be used to test theory, with findings either supporting or refuting the theory.

Qualitative research has made substantial contributions to building theory in management (Eisenhardt, 1989; Weick, 1989; Yin, 1989). According to Bluhm, Harman, Lee, and Mitchell (2011), more qualitative research has been published in top-tier management journals in the United States in the past decade than in the two decades preceding it. Qualitative articles even made up the majority on the "interesting research list" published by the Academy of Management Journal (Bartunek, Rynes, \& Ireland, 2006).

Qualitative research is a method of gathering information from subjects to gain a better understanding of human behavior and the potential reasons that govern said behavior. In qualitative research, one starts with a central question rather than a prediction and attempts to find the answer, basically trying to understand why (Creswell, 2009). Nuttall, Shankar, and Beverland (2011) stated that qualitative research is used to become more knowledgeable about subjects that researchers are interested in and should be used to gain direct experience in an area to be studied. Essentially, qualitative research explores complex human interactions to understand lived experiences and has a special value for exploring sensitive topics or topics based on personal values, such as religion, sexuality, gun control, or the death penalty (Nuttall et al., 2011). While quantitative methods could address such issues, they would likely provide limited data, such as being able to answer the question, "Do you support the death penalty?" Exploring such a topic in greater depth requires qualitative methods.

Qualitative research plays a key role in pushing past previous limits of theories regarding quantitative empiricism (Doz, 2011). One unique quality of qualitative research is that it can provide information about hidden areas of decision making by addressing complex items, such how or why (Creswell, 2009). For example, one might observe several murders in the street of a specific town. One could observe this over time and possibly deduce the frequency and time of the murders to avoid the situation. However, it might be more valuable to understand the underlying cause-why the murders were happening - possibly creating the opportunity to eliminate the behavior altogether.

Qualitative research can contribute to theories in many ways. First, qualitative research can help provide thick and rich descriptions of phenomena, generating deeper thought (Weick, 2007). Qualitative research also provides a backstop or safeguard against the accepted norms because researchers ask more probing questions rather than standardly accepted questions (Doz, 2011). As theory development is an iterative process, qualitative methods 
can aid in providing refinement to key concepts and results by supplying additional insight. Qualitative methods can also test theory using alternative theoretical lenses to investigate a phenomenon and provide additional insight about the theory and its interactions (Bluhm et al., 2011; Lee, Mitchelle, \& Sablynski, 1999). Accoring to Eisenhardt (1989), case study methods involving qualitative research have a high likelihood of generating novel theory.

Ellis and Levy (2008) formulated seven constructs that describe and help quantify the importance and contribution of research for refining and explaining theory. These constructs are establishment of causal relationship, examination of element, method of creating product through developmental study, constructs development, predictive model development, efficacy evaluation, and examination of the impact of time on the nature of the documented problem in a longitudinal study (Ellis \& Levy, 2008).

In general, there are several ways that research contributes to theory. The first is in the creation of theory-observations from research can be used to formulate theory. Research can also be used to validate a theory or to refute a theory. However, research needs not specifically be applied to support or refute theory; it can also serve as a tool to provide additional insight into elements of a theory to facilitate further refinement of the theory.

\subsection{Example of How a World View of Theory Adds to a Field of Study}

To apply this concept, this section explores how the world view of a theory could contribute to a generic marketing study on motivation. Of the three views offered by Stam (2007), reductionism, instrumentalism, and realism, reductionism would make a significant contribution to a motivation-based research project and has been applied to make significant contributions to the field of business and many other disciplines. A proposed topic of an example study would be "A case study on the motivations of parents who buy SAT prep courses for their children." This study might be used to contribute to the body of knowledge around third-party college preparatory services using the consumer behavior theory and the black box model and applying the reductionism paradigm.

Consumer behavior refers to the study of individuals, organizations, and groups to understand how they obtain and use consumer products and services, as well as the ideas needed to affect or satisfy these choices (Sandhusen, 2000). The black box model represents the interactions among consumer traits, stimuli, decision processes, and consumer responses. The elements of buyer's response and environmental factors can be empirically observed; however, the items inside the buyer's black box cannot.

The intent of this hypothetical study would be to use a qualitative study and reductionist methods to understand buyer motivation for purchasing SAT preparatory services for children. Applying reductionism methods to the study of the motivation component of the black box would provide valuable insight into the reasons that parents buy these services for their children. Examining this single component would shed light on one element of the black box, adding more clarity to the theoretical picture. In addition to possibly adding to the body of knowledge around consumer theory and the black box model to help refine the theory, these data would also be used to add to the body of knowledge on business and college preparatory services.

Though reductionism could help address the proposed study and has been used to help make significant contributions to science in general, it has been subjected to criticism (Gianfranco, 2012). Two issues with reductionism are that not all things can be reduced to components (Gianfranco, 2012) and reductionism is not effective in working with complex social systems, particularly those involving feedback loops (Sarker, 2010). Alvesson and Kärreman (2011) asserted that reductionism "fails to recognize the leveled 'nature' of social reality, that is, the assumption that social reality is productively understood as consisting of irreducible dimensions or levels" (p. 1196). As the tenets proposed by reductionists are that everything can be separated into its components and that the components are interchangeable (Nadler, 2004), an issue arises.

Clearly, some items cannot be broken into their components. For example, anger cannot be broken easily into components. Alvesson and Sköldberg (2009) suggested that this problem might be addressed by adapting different lines of interpretation, assuming different angles, or even applying a different vocabulary, ostensibly suggesting that the approach might be useful in certain defined situations. One should consider that an approach can work for some situations even if it does not apply to all situations. Early Greek philosophers proposed the atom as the smallest individual part of matter, and later, scientists discovered subatomic particles such as neutrons and electrons. Nonetheless, atomic theory evolved rather than ceasing to exist, as should the appropriate components of reductionism.

Another issue that makes reductionism challenging is complex social systems. Sarker (2010) acknowledged a 
middle ground, stating that microlevel accounts can explain social phenomenon, but macrolevel accounts might be irreducible. Complex social interactions with many potential feedback loops simply may not be reducible. Further, Gianfranco (2012) warned that reductionist attitudes can cause observers to ignore necessary transformative processes, which can have catastrophic effects when interacting with social systems, such as a family, school, or business. For example, family unit components may be identified as mother, father, and child, which might not provide data relevant to all families, as each type of family member might be different or have differing perspectives. A family may have a grandparent instead of a parent, and one could not exchange fathers in two different families and expect the same results (family experience).

Even though reductionism may have criticisms and challenges, the approach is not without merit and has a viable role to play in research. Pellegrinelli and Webster (2011) noted reductionism as a key element in the development of the functionalist paradigm for project management. Baalen and Karsten (2012) acknowledged that abstraction is a critical management technique derived from reductionism. Harlow's (2009) isolation of the problem statement as central to research methodology is an example of the application of reductionism. As stated, Ellis's and Levy's (2008) seven constructs for the framework of problem-based research and Wacker's (1998) four constructs of a theory are further examples.

\subsection{Example of Widely Applied Theory}

A theory that has made significant contributions to the field of business is grounded theory. Grounded theory is a widely used method in qualitative studies (Martin \& Turner, 1986; Ng \& Hase, 2008). Grounded theory is more than simply a research tool to add credibility to a study (Lee \& Fielding, 1996); grounded theory offers opportunities for researchers in the field of management (Charmaz, 2006) to produce generalized results that can indicate a holistic view of the data examined and drive the creation of innovative theory (Fendt \& Sachs, 2008).

However, grounded theory is rooted in many controversies when used for practical application (Fendt \& Sachs, 2008). This is due to the core tenet of grounded theory that has the researcher explore the environment without a stated problem, which directly contradicts Harlow's (2009) point of view. Another controversy surrounding grounded theory is that the original authors, Glaser and Strauss (1967), are split on the concept and its application (Partington, 2003; Ng, 2005; Ng \& Hase, 2008). According to Ng and Hase (2008), there are two distinct approaches to applying grounded theory: the original Glasarian approach and the later-refined Straussian approach that provides step-by-step procedures and techniques for analyzing data. Lastly, grounded theory is criticized for taking substantial time to complete, a luxury that researchers often are not afforded.

\section{Discussion}

The term theory is widely used across disciplines (Gelso, 2006; Stam, 2007). Inconsistent use within and across disciplines creates confusion around the definition of theory. The broad nature of theory may cause researchers to confuse theorizing with theory (Weick, 1995). Evidence of this inconsistency is the existence of articles discussing theory from the perspective of what theory is not, rather than trying to define theory, such as Sutton and Staw (1995) and Weick (1995).

In addition to world views, researchers have more tactical views on what constitutes good theory. Concerns seem to stem from the questions of quality and applicability of theory. Stam (2007) asserted that theory should focus on practice and outcome. Gelso (2006) emphasized that theory must go beyond mere explanation and delve into why variables relate and influence each other, a critical step to adding scientific value. Wacker (1999) called for theory to provide answers to the common questions faced by researchers.

Views and use of theory and research vary by field. Gelso (2006) criticized the use of theories in psychology as large theoretical systems, such as behaviorism, psychoanalysis, and humanism. Gelso asserted that these systems often are combined with personality theories to create a theoretical concoction of untestable life philosophies, statements of faith, and grand theories. Stam (2007) offered a possible explanation for the lack of rigor in psychological theory, suggesting that the term theory is used in an overly broad manner and that researchers may not abandon older theoretical concepts early enough. Consequently, Creswell (2009) and Gelso supported minitheories, parts of these broader systems that are theoretical statements, as effective methods for interpreting specific behavior for psychological research.

Whereas psychology researchers seem to condemn theory for obscuring practice (Gelso, 2006; Stam, 2007, 2010), business researchers, specifically marketing researchers, cite an overemphasis on practical application as potentially damaging theory development (Ardley, 2011; Burton, 2005). Marketing grand theory consistently fails to provide adequate insight into real-world marketing problems (Ardley, 2011). Often, research on successful entrepreneurial ventures indicates marketing techniques that are not based on current marketing 
theory (Ardley, 2011).

Several views are offered as the reason for poor theory development. Business and marketing researchers do not have time for theory development (Burton, 2005). Theory may be seen as a "second-class citizen" and may not be viewed as useful for stakeholders in business (Wacker, 2009). Researchers may grow weary due to the iterative nature of theorizing and could accept results too early in the process to create a robust theory (Weick, 1995). Alternatively, the lack of agreement on what constitutes theory could inhibit the ability of researchers to identify and agree on definitions of good theory within disciplinary groups.

Older, more established paradigms proffer core guidance for key research and theoretical concepts. Instrumentalism provides guidance for discovery, realism provides guidance for theory validation, and reductionism provides guidance for exploration (Cacioppo, Semin, \& Berntson, 2004). Instrumentalists provide theoretical orientation where sound theories are the tools for discovery (Davies, 2008). Realists provide theoretical orientation where existing theories can be validated (Ramoglue, 2013). Reductionists provide theoretical orientation where additional observations can be made when exploring phenomena (Burgelman, 2011; Link, 2000; Wood \& Caldas, 2011). Even amid controversy, concepts such as reductionism and grounded theory can be used to create valuable contributions to several disciplines.

Research and theory are inextricably linked (Fawcett \& Downs, 1986). The process of retroduction enables theory and research work through a reciprocating cycle to generate scientific discovery (Harlow, 2009). Research is used to generate observations that can be applied to create theory. Theory is then utilized to create the opportunity for additional research, which can be used to validate, refine, or refute theory. This creates a self-reinforcing cycle of discovery that drives the development of new knowledge.

\section{Conclusion}

Theory and research are far-reaching concepts that are interrelated. Scholars may disagree on the nature and use of theory and research, especially across disciplines, but all seem to respect the importance of the cycle. As researchers gain new knowledge and adapt new methods, older and even controversial theory and research methods often continue to be used to significantly contribute to their fields. Theory provides a method of predicting the interactions of phenomena, and research enables the testing of theory and the discovery of new observations. This interrelationship between theory and research becomes, in effect, an engine to help produce new knowledge.

\section{Acknowledgments}

I would like to thank Allison Humphries for her assistance in manuscript copyediting.

\section{References}

Aliaga, M., \& Gunderson, B. (2000). Interactive statistics. Saddle River, NJ: Prentice Hall.

Alvesson, M., \& Sköldberg, K. (2009). Reflexive Methodology (2nd ed.). London: Sage.

Alvesson, M., \& Kärreman, D. (2011). Organizational discourse analysis - Well done or too rare? A reply to our critics. Human Relations, 64(9), 1193-1202. http://dx.doi.org/10.1177/ 0018726711408630

Ardley, B. (2011). Marketing theory and critical phenomenology. Marketing Intelligence \& Planning, 29(7), 628-642. http://dx.doi.org/10.1108/02634501111178668

Austin, D. (1978). Educational paradoxes and possibilities. doi:10.1300/J079v02n02_02

Baalen, P., \& Karsten, L. (2012). The evolution of management as an interdisciplinar field. Journal of Management History, 18(2), 219-237. http://dx.doi.org/10.1108/17511341211206861

Bartunek, J. M., Rynes, S. L., \& Ireland, R. D. (2006). What makes management research interesting and why does it matter? Academy of Management Journal, 49(1), 9-15. http://dx.doi.org/10.5465/AMJ.2006.20785494

Bertrand, J. W., \& Fransoo, J. C. (2002). Operations management research methodologies using quantitative modeling. International Journal of Operations \& Production Management, 22(2), 241-264. http://dx.doi.org/10.1111/j.1467-6486.2010.00972.x

Burgelman, R. A. (2011). Bridging history and reductionism: A key role for longitudinal qualitative research. Journal of International Business Studies, 42(5), 591-601. http://dx.doi.org/10.1057/jibs.2011.12

Burton, D. (2005). Marketing theory matters. British Journal of Management, 16, 5-18. http://dx.doi.org/10.1111/j.1467-8551.2005.00432.x 
Charmaz, K. (2006). Handboook of qualitative research. Thousand Oaks, CA: Sage.

Creswell, J. W. (2009). Research Design (3rd ed.). Thousand Oaks, CA: Sage.

Davies, S. (2008). Intellectual and political landscape: The instrumentalism debate. Cultural Trends, 17(4), 259-265. http://dx.doi.org/10.1080/09548960802615398

DiMaggio, P. J., \& Powell, W. W. (1983). The iron cage revisited: Institutional isomorphism and collective rationality in organizational fields. American Sociological Review, 48(2), 147-160. http://dx.doi.org/10.1016/S0742-3322(00)17011-1

Doz, Y. (2011). Qualitative research for international business. Journal of International Business Studies, 42(5), 582-590. http://dx.doi.org/10.1057/jibs2011.18

Du, R. Y., \& Kamakura, W. A. (2012). Quantitative trendspotting. Journal of Marketing Research, 49(4), 514-536. http://dx.doi.org/10.1509/jmr.10.0167

Edmondson, A. C., \& McManus, S. E. (2007). Methodological fit in management field research. Academy of Management Review, 32(4), 1155-1179. Retrieved from http://aom.org/amr/

Eisenhardt, K. (1989). Building theories from case study research. Academy of Management Review , 14(4), 532-550. Retrieved from http://aom.org/amr/

Ellis, T. \& Levy, Y. (2008). Framework of problem-based research: A guide for novice researchers on the development of a research-worthy problem. Informing Science: The International Journal of an Emerging Transdiscipline, 11, 17-33. Retrieved from http://inform.nu

Fawcett, J., \& Downs, F. (1986). The relationship of theory and research. Norwalk, CT: Appleton Century Crofts.

Fendt, J., \& Saschs, W. (2008). Grounded theory method in management research: User's perspectives. Organizational Research Methods, 11(3), 430-455. Retrieved from http://orm.sagepub.com/content/11/3/430.short

Fischer, C., Winter, R., \& Wortmann, F. (2010). Design theory. Business \& Information Systems Engineering, 2(6), 387-390. doi:10.1007/s12599-010-0128-2

Galtung, J. (1985). Theory and methods of social research. London: Gorege Allen \& Unwin.

Gay, B., \& Weaver, S. (2011). Theory building and paradigms: A primer on the nuances of theory construction. American International Journal of Contemporary Research, 1(2), 24-32. Retrieved from http://www.aijcrnet.com/

Gelso, C. (2006). Applying theories to research: The interplay of theory and research in science. In F. T. Leong \& J. T. Austin (Eds.), The psychology research handbook. Thousand Oaks, CA: Sage.

Gianfranco, M. (2012). Knowledge to manage the knowledge society. The Learning Organization, 19(4), 350-368. http://dx.doi.org/10.1108/09696471211226707

Harlow, E. (2009). Contribution, theoretical. Encyclopedia of Case Study Research. http://dx.doi.org/10.4135/9781412957397

Henderikus, S. (2007). Theoretical psychology. Thousand Oaks, CA: Sage.

Holten, E. F., \& Lowe, J. S. (2007). Toward a general research process for using Dublin's theory building model. Human Resource Development Review, 6, 297-320. http://dx.doi.org/10.1177/ 1534484307304219

Kaplan, A. (1964). The conduct of inquiry: Methodology for behavioral science. New York, NY: Thomas Y. Crowell.

Lee, R. M., \& Fielding, N. (1996). Qualitative data anlaysis: Representation of a technology: A comment on Coffey, Holbrook, and Atkinson. Sociology Research Online, 1(4), Retrieved from http://www.socresonline.org.uk/1/4/lf.html

Lee, T. W., Mitchelle, M. R., \& Sablynski, C. J. (1999). Qualitative research in organizational and vocational psychology. Journal of Vocational Behavior, 55(2), 161-187. http://dx.doi.org/10.1006/ jvbe.1999.1707

Leedy, P. D., \& Ormond, J. E. (2005). Practical research: Planning and design (8th ed.). Upper Saddle River, NJ: Prentice Hall.

Link, G. (2000). Reductionism as resource-consious reasoning. Erkenntnis, 53(1-2), 173-193. http://dx.doi.org/10.1023/A:1005610001124 
Littlejohn, S. W. (1989). Theories of Human Communication (3rd ed.). Belmont, CA: Wadsworth.

Lynham, S. A. (2002). The general method of theory-building research in applied disciplines. Advances in Developing Human Resources, 4(3), 221-235. http://dx.doi.org/10.1177/ 1523422302043002

Malmi, T., \& Granlund, M. (2009). In search of management accounting theory. European Accounting Review, 18(3), 597-210. http://dx.doi.org/10.1080/09638180902863779

Martin, P. Y., \& Turner, B. A. (1986). Grounded theory and organizational research. The Journal of Applied Behavioral Science, 22(2), 141-157. Retrieved from http://jab.sagepub.com/

Mink, O. G. (1992). Creating new organizational paradigms for change. The International Journal of Quality \& Reliability Management, 9(3), 21. http://dx.doi.org/10.1108/EUM0000000001645

Nadler, G. (2004). Taking a holistic path. Industrial Management, 46(6), 26-31. Retrieved from http://law-journals-books.vlex.com

National Academy of Sciences. (1999). Science and creationism (2nd ed.). Washington, DC: National Academy Press.

$\mathrm{Ng}, \mathrm{K}$. (2005). Managing collaborative synergy in the crane industry. Grounded Theory Review, 4(3), 81-103. Retrieved from http://groundedtheoryreview.com

Ng, K., \& Hase, S. (2008). Grounded suggestions for doing a grounded theory business research. Electronic Journal of Business Research Methods, 6(2), 155-170. Retrieved from http://www.groundedtheoryreview.com/

Nuttall, P., Shankar, A., \& Beverland, M. B. (2011). Mapping the unarticulated potential of qualitative research. Journal of Advertising Research, 51153-163. http://dx.doi.org/10.2501/jar-51-1-153-166

Partington, D. (2003). Building grounded theories of management action. British Journal of Management, 11(2), 91-102. http://dx.doi.org/10.1111/1467-8551.00153

Pellegrinelli, S., \& Webster, R. M. (2011). Multi-paradigmatic perspectives on a business transformation program. Project Management Journal, 42(6), 4-19. http://dx.doi.org/10.1002/ pmj.20275

Ramoglu, S. (2013). On the misuse of realism in the study of entrepreneurship. The Academy of Management Review, 38(3), 463-465. http://dx.doi.org/10.5465/amr.2012.0371

Ratcliffe, J. W. (1983). Notations of validity in qualitative research methodology. Science Communication, 5(2), 147-167. http://dx.doi.org/10.1177/107554708300500201

Rein, K., Kotler, P., \& Shields, B. (2006). The elusive fans: Reinventing sports in a crowded marketplace. Blacklich: McGraw-Hill.

Sandhusen, R. L. (2000). Marketing (4th ed.). Hauppauge, NY: Barron's Educational Series.

Sarker, S. (2010). An alternative to methodical individualism: A non-reductionist approach to studying technology adoptions by groups. MIS Quarterly, 34(4), 779-812.

Shoemaker, P. J., Tankard, J. W., \& Lasorsa, D. L. (2004). How to build social science theories (4th ed.). Thousand Oaks, CA: Sage. http://dx.doi.org/10.4135/9781412990110

Stam, H. (2007). Theoretical psychology. In The international handbook of psychology. Thousand Oaks, CA: Sage. http://dx.doi.org/10.4135/9781848608399

Stam, H. (2010). Theory. In Encyclopedia of research design. Thousand Oaks, CA: Sage. http://dx.doi.org/10.4135/978142961288

Sutton, R. I., \& Staw, B. M. (1995). What theory is not. Administrative Science Quarterly, 40(3), 371-384. http://dx.doi.org/10.2307/2393788

Thomas, J. E. (2017). Exploring buyer motivation to improve management, marketing, sales, and finance practices in the martial arts industry. International Journal of Marketing Studies, 9(2). http://dx.doi.org/10.5539/ijms.v9n2p12

Wacker, J. (1998). A definition of theory: Research guidelines for different theory-building research methods in operations management. Journal of Operations Management, 16(4), 361-385. http://dx.doi.org/10.1016/S0272-6963(98)00019-9

Weick, K. E. (1989). Theory construction as disciplined imagination. Academy of Management Review, 14(4), 516-531. http://dx.doi.org/10.2307/258556 


\section{Copyrights}

Copyright for this article is retained by the author(s), with first publication rights granted to the journal.

This is an open-access article distributed under the terms and conditions of the Creative Commons Attribution license (http://creativecommons.org/licenses/by/3.0/). 